\title{
miRNA-195 sensitizes human hepatocellular carcinoma cells to 5-FU by targeting BCL-w
}

\author{
XIAOYAN YANG ${ }^{1}$, JIE YIN $^{1}$, JIA YU $^{1}$, QIONG XIANG ${ }^{1}$, YUNMEI LIU $^{1}$, SHENSONG TANG $^{1}$, \\ DUANFANG LIAO ${ }^{1}$, BINGYANG ZHU ${ }^{1}$, XUYU ZU ${ }^{2}$, HUIFANG TANG $^{2}$ and XIAOYONG LEI ${ }^{3}$ \\ ${ }^{1}$ Institute of Pharmacy and Pharmacology, University of South China, 28 Changsheng Road, Hengyang; ${ }^{2}$ The \\ First Affilitated Hospital of University of South China, 69 Chuanshan Road, Hengyang; ${ }^{3}$ College of Pharmacy \\ and Life Science, University of South China, 28 Changsheng Road, Hengyang, Hunan 421001, P.R. China
}

Received June 27, 2011; Accepted August 16, 2011

DOI: $10.3892 /$ or.2011.1472

\begin{abstract}
The role of microRNA-195 in developing acquired drug resistance in hepatocellular carcinoma cells was investigated. Expression profiling of miRNAs revealed a limited set of miRNAs with altered expression in drug resistant hepatocellular carcinoma cell line BEL-7402/5-FU compared to its parental BEL-7402 cell line. Real-time PCR confirmed down-regulation of miRNA-195 in BEL-7402/5-FU cells. Overexpression of miRNA-195 sensitized BEL-7402/5-FU cells to anticancer drugs. Consistent with these findings, miR-195 antisense oligonucleotide induced drug resistance in BEL-7402/5-FU cells. Also, the basal levels of the antiapoptotic protein Bcl-w were high in BEL-7402/5-FU cells and miR-195 overexpression repressed $\mathrm{Bcl}-\mathrm{w}$ protein level and inhibited the luciferase activity of a Bcl-w 3' untranslated region-based reporter construct in both BEL-7402/5-FU and BEL-7402 cells. These results indicate that miR-195 could improve the drug sensitivity at least in part by targeting Bcl-w to increase cell apoptosis in hepatocellular carcinoma cells.
\end{abstract}

\section{Introduction}

Hepatocellular carcinoma (HCC) is one of the top 10 most prevalent cancers worldwide (1) and accounts for $80-90 \%$ of liver cancers (2). Like other cancers, aberrant gene regulation features are significantly present in HCC. However, effec-

Correspondence to: Dr Xiaoyong Lei, College of Pharmacy and Life Science, University of South China, 28 Changsheng Road, Hengyang, Hunan 421001, P.R. China

E-mail: lei_xiaoyong@yahoo.com.cn

Abbrevations: BEL-7402/5-FU, 5-fluorouracil-resistant human liver adenocarcinoma cell line; Bcl-2, B cell lymphoma/leukemia-2; Bcl-XL, B-cell lymphoma/leukemia-extra long; miRNA, microRNA; MTT, 3-[4,5-Dimethylthiazolzyl]-2,5-diphenyl tetrazolium bromide; Q-RT-PCR, quantitative real-time reverse transcription polymerase chain reaction

Key words: miR-195, Bcl-w, 5-Fluorouracil, hepatocellular carcinoma tive chemotherapeutic agents for this disease have not been developed. Recent studies have focused on the role of drug resistance in HCC treatment. Most chemotherapeutic drugs act as an apoptosis inducer. Consequently, the development of resistance to cytotoxic drugs by cancer cells may be due to cellular resistance to apoptosis. The commitment of apoptosis is largely a mitochondrial event controlled by proteins in the Bcl-2 family (3). Bcl-XL is an anti-apoptotic member of the Bcl-2 family that is located mainly on the outer membrane of mitochondria (4). The overexpression of Bcl-w, Bcl-XL and $\mathrm{Bcl}-2$ is considered to be the mechanism by which tumor cells acquire resistance to apoptosis.

Numerous pathways (e.g., proliferation, cell cycle regulation, apoptosis, and angiogenesis) were identified to be dysregulated during hepatocarcinogenesis in HCC patients by using microarray analysis (5). In particular, apoptosis regulation (6) has been extensively described as a crucial event in the carcinogenetic process that leads to HCC development. Recently, a new class of small non-coding RNAs (miRNA) has been discovered (7) and is shown to be implicated in carcinogenesis (8). By binding to the complementary sequences of their target mRNAs (mostly in the 3'-UTR), miRNAs were able to induce mRNA degradation or translational repression (9). Multiple G1/S transition-related molecules, including cyclin D1, CDK6 and E2F3, were characterized as direct functional targets of miR-195 (10). miR-195 was further suggested to exert its proapoptotic function mainly through targeting Bcl-2 expression (11). Bcl-w, an anti-apoptotic Bcl-2 family member (12) was identified as harboring a putative miR-195 binding site in its 3'-UTR by using online prediction algorithmas. Bcl-w expression was modulated by Met/HGF receptor (c-met) in human colorectal cancers (13). Moreover, Bcl-w was up-regulated in autoimmune hepatitis (AIH)-associated cirrhosis (14) and may play a role in hepatocarcinogenesis.

In the present study, we demonstrated that a limited set of miRNAs were differentially expressed in a drug-resistant human hepatocellular carcinoma cell line BEL-7402/5-FU, compared to its parental cell, BEL-7402. MiR-195, one of the down-regulated miRNAs in BEL-7402/5-FU cells, was demonstrated to play a role in the development of drug resistance in hepatocellular carcinoma cells by targeting the antiapoptotic gene, Bcl-w. 


\section{Materials and methods}

Materials. PcDNATM6.2-GW/miR linear vector was purchased from GenePharma (Shanghai, China). Human hepatocellular carcinoma cell line BEL-7402 and its drug resistant line BEL-7402/5-FU were purchased from Nanjing KeyGen Biotech. Co., Ltd. (Nanjing, China).

Cell lines and cultures. Both human hepatocellular carcinoma cell line, BEL-7402 and its drug resistant line BEL-7402/5-FU were cultured in RPMI-1640 medium supplemented with $10 \%$ fetal calf serum (Gibco BRL, Grand Island, NY) in a humidified atmosphere containing $5 \% \mathrm{CO}_{2}$ at $37^{\circ} \mathrm{C}$. To maintain the drug resistance phenotype, 5-FU (with final concentration of $20000 \mathrm{ng} / \mathrm{ml}$ ) was added to the culture media for BEL-7402/5-FU cells.

MicroRNA microarray and hybridization analysis. Microarray was performed at KangChen Bio-tech (Shanghai, China). RNA extraction: total RNA from BEL-7042 cells and BEL-7042/5-Fu cells were prepared using TRIzol (Invitrogen CA, USA) following the manufacturer's protocol, where propanol was replaced by ethanol for RNA precipitation. RNA quality was measured using denaturing agarose gel electrophoresis.

MiRNA labeling: miRCURY ${ }^{\mathrm{TM}}$ Array labeling ke, Exiqon: total RNA $(5 \mu \mathrm{g})$ was ligated to an RNA-linker (p-rUrUrUdACy3-dye Dharmacon) labeled at $3^{\prime}$-end with $3^{\mathrm{TM}}$ fluorescent T4 RNA ligase overnight at $37^{\circ} \mathrm{C}$.

Microarray preparation and hybridization: miRCURY ${ }^{\mathrm{TM}}$ Array microarray kit (cat\# 208002V9.2) was purchased from Exiqon (Denmark); Hybridization Chamber (Cat\#40080) was obtained from Corning (Japan), and Bioarray LifterSlip coverslip was purchased from Ambion. Spotted microarray slides were processed using an automated hybridization station, which facilitated sample processing and hybridization standardization. Taking into account the different hybridization kinetics of DNA and LNA RNA-modified capture probes, the hybridization conditions were individually set optimally for LNA-RNA and DNA-based arrays. Microarrays with immobilized RNA-LNA-modified capture probes were hybridized at $55^{\circ} \mathrm{C}$ using microarray hybridization solution containing $30 \%$ formamide. Microarrays with immobilized DNA-oligonucleotides were hybridized at $42^{\circ} \mathrm{C}$ in hybridization solution containing $10 \%$ formamide.

Image acquisition and quantification: the slides were scanned using the Genepix 4000B (Axon Instruments). The $635 \mathrm{~nm}$ laser was used. The data were analyzed in Genepix Pro 6.0 (Axon Instruments) and saved as Excel files. GeneSpring 7.2 (Silicon Genetic) was used for further data analysis. Changes in expression, either 2-fold greater or less, were considered to be differentially expressed. All data used for analysis had a signal-to noise ratio of $>2$, an average sum intensity $50 \%$ higher than that of the negative control spots, and a regression ratio of $<0.5$, as previously reported.

Construction of miR-195 expression plasmids. PcDNATM6.2-GW/miR linear vector was purchased from GenePharma (Shanghai), and hsa-miR-195 ${ }^{\mathrm{TM}}$ insert sequence with the following sense: 5'-CACTGAC
TGACGCCAATATCTGTGCTGCTA-3' and antisense sequences were: 5'-ACTGACTGACTAGCAGCAGA AATATTGGC-3' were chemically synthesized. A negative control vector that expresses a hairpin shRNA with limited homology to any known sequences of human genome was commercially available (GenePharma). Plasmid DNA was purified by cesium chloride bromide gradient centrifugation. The purified DNA was diluted to $1 \mathrm{mg} / \mathrm{ml}$ and stored at $-20^{\circ} \mathrm{C}$ until used.

Cell culture and transfection. BEL-7402 and BEL-7402/5-FU cells were cultured in RPMI-1640 medium (Gibco-BRL) with $10 \%$ fetal bovine serum (Hyclone, Logan), and for BEL-7402/5-FU $2 \mu \mathrm{g} / \mathrm{ml}$ (QiLu, Shangdong, China) was added. Eighteen hours before transfection, cells were seeded into wells of a 6-well plate that contained antibiotic-free medium; at the time of transfection, the cell confluence was routinely $90-95 \%$. Transfection was carried out according to the manufacturer's protocol. hsa-miR-195 ${ }^{\mathrm{TM}}(4 \mu \mathrm{g})$, anti-hsamiR-195 $(4 \mu \mathrm{g})$ and negative plasmid $(4 \mu \mathrm{g})$ carrying green fluorescent protein (GFP) were diluted with $100 \mu 1$ OPTI-MEM (Invitrogen) or $10 \mu \mathrm{l}$ Lipofectamine 2000 (Invitrogen) with $100 \mu \mathrm{l}$ OPTI-MEM. After $5 \mathrm{~min}$, the dilutions were mixed together and incubated at $37^{\circ} \mathrm{C}$ for $20 \mathrm{~min}$, then dispensed into each well. Forty-eight hours after transfection, fluorescence microscope was used to detect the transfection efficiency.

Real-time quantitative RT-PCR. The expression level of miR-195 was measured in cells transfected with pcM-195s, pcM-195a, or miR-NC by using the NCode ${ }^{\mathrm{TM}}$ miRNA FirstStrand cDNA Synthesis Kit and NCode SYBR Green miRNA qRT-PCR Kit (Invitrogen, USA). The level of U6 RNA was measured and used to normalize the relative abundance of miR-195. The cycle number at which the reaction crossed an arbitrarily placed threshold (CT) was determined for each gene, and the relative amount of each miRNA to U6 RNA was calculated using the equation $2-\Delta \mathrm{CT}$, where $\Delta \mathrm{CT}=$ (CTmiRNA - CT5s) (15). Relative gene expression was multiplied by U6 to simplify the presentation of the data.

The expression levels of Bcl-w, Bcl-2, Bcl-XL and Bax were measured in cells $48 \mathrm{~h}$ post-transfection using High Capacity cDNA Reverse Transcription kit and Power SYBR Green PCR master Mix (Applied Biosystems).

MiR-195 target prediction. Given the limitations of any single prediction program, we used two separate prediction programs (Targetscan 5.1 and PicTar) to identify common predicted targets for miR-195. Target Scan 5.1 utilizes matching in the $3^{\prime}$ UTR for only 7 mer and 8mer interactions sites.

Construction of 3'-UTR reporter plasmids and luciferase assays. The part of the 3'UTR of Bcl-w mRNA containing the intact miR-195 recognition sequence (at nucleotide 777-783 of 3'UTR) was amplified by a pair of primers (F: 5'-CCGCTCGAGCTTTCCAGAAAGTGATTGGCAAG-3'; R: 5'-ATAAGAATGCGGCCGCCCTTGGAAAGTGCAG CAGTGAG-3') and subcloned into XhoI and Not I sites of psiCheck-2 vector (Promega, USA) immediately downstream of the luciferase gene to form a psi-Bcl-w-3'UTR construct. The psi-Bcl-w/mut-3'UTR reporter construct 
with point mutations in the seed sequence as underlined (5'-TGCTGCT-3') was synthesized using the site-directed mutagenesis kit (Stratagene, La Jolla, CA). For the luciferase assay, BEL-7402 or BEL-7402/5-Fu cells were cultured in 24-well plates and each transfected with $0.1 \mu \mathrm{g}$ of either miR-195s, miR-195a or negative control, which contained the Renilla luciferase gene, and $30 \mathrm{pmol} \mathrm{miR}-195 \mathrm{~s}$, miR195a, or negative control. Transfection was done using Lipofectamine 2000 (Invitrogen) and Opti-MEM I reduced serum medium (Life Technologies) in a final volume of $0.6 \mathrm{ml}$. At $24 \mathrm{~h}$ after transfection, firefly and Renilla luciferase activity were measured using the Dual Luciferase Reporter Assay (Promega). Each transfection was repeated twice in triplicate. Relative protein levels were expressed as Renilla/firefly luciferase ratios.

Western blotting. Cell lysates were centrifuged at $10,000 \mathrm{x} \mathrm{g}$ for $10 \mathrm{~min}$ at $4^{\circ} \mathrm{C}$. Protein content in the supernatants was determined by a BCA protein assay kit (Pierce, Rockford, IL). Equal amounts of lysate protein were run on $10 \%$ SDS-PAGE and transferred to PVDF membranes (Amersham-Pharmacia Biotech). After blocking, we then incubated PDVF membranes with rabbit, anti-Bcl-w, anti-Bcl-XL, and anti-Bcl-2 primary monoclonal antibody at dilution of 1:1000 and rabbit antiBax, polyclonal antibody at dilution of 1:1000 (Cell Signaling Technology, USA) overnight at $4^{\circ} \mathrm{C}$ and further incubated for $1 \mathrm{~h}$ with horseradish peroxidease conjugated anti-rabbit secondary antibody at dilution of 1:1000. Bound antibodies were detected by enhanced chemiluminescence (ECL) kit with a Lumino Image Analyzer (Taitec, Tokyo, Japan).

Flow cytometry analysis. All cells were treated with 5-fluorouracil (5-FU), washed twice with PBS and fixed with 70\% ethanol overnight at $4^{\circ} \mathrm{C}$. Then the cells were washed once with PBS and stained with $800 \mu \mathrm{l}$ propidium iodide $(50 \mathrm{mg} / \mathrm{l}$, Sigma, St. Louis, MO) at room temperature for $30 \mathrm{~min}$ to determine apoptosis by flow cytometry (EPICS-XL, Beckman Coulter, Fullerton, CA) and the data were analyzed with CellQuest software version 3.3 (Becton-Dickinson, San Jose, CA).

Cytotoxicity analysis. Cells from the above groups were seeded into a 96 -well plate at $1 \times 10^{4}$ cells per well. After $24 \mathrm{~h}$, various concentrations of 5-FU were added and the cells were incubated for another $24 \mathrm{~h}$. Then the cells were treated with MTT $\left(5 \mathrm{~g} / 1\right.$, Sigma, USA) for $4 \mathrm{~h}$ at $37^{\circ} \mathrm{C}$, and $200 \mu 1$ dimethysl sulphoxide (DMSO) was added in each well for $10 \mathrm{~min}$. The reaction was optically monitored at $570 \mathrm{~nm}\left(\mathrm{~A}_{570}\right)$ using a 96-well microtitre plate reader (Pharmacia, Piscataway, NJ). All experiments were carried out in triplicate. The inhibitory rate (IR) of Bel-7402/5-FU cells was calculated according to the equation as following: $\operatorname{IR}(\%)=\left[\mathrm{A}_{570}\right.$ (control) $\left.-\mathrm{A}_{570}(\mathrm{drug})\right] / \mathrm{A}_{570}$ (control) $\times 100 \%$, where $\mathrm{A}_{570}$ (control) was the absorbance in miR-195s or miR-195a or negative vector transfected cells or untreated cells, and $\mathrm{A}_{570}$ (drug) was the absorbance in the drugtreated group.

Statistical analysis. Statistical analysis was performed using SPSS software (Version 14.0, SPSS Incorporation,

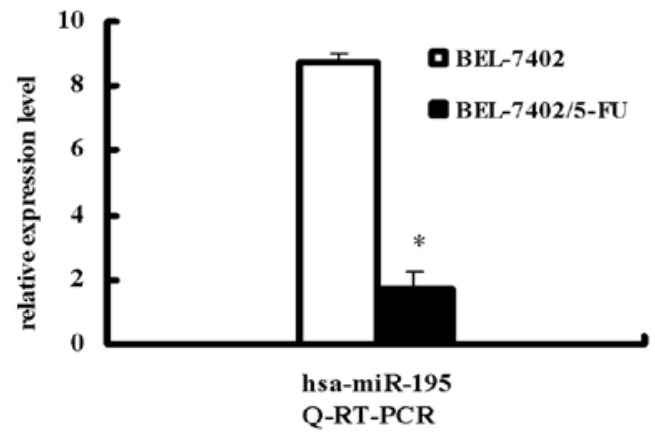

Figure 1. BEL-7405/5-FU cells express lower miR-195 than BEL-7402 cells. Real-time RT-PCR analysis was carried out to validate the microarray results. Triplicate assays were performed for RNA sample and the relative amount of miRNA was normalized to U6 snRNA. ${ }^{*} \mathrm{P}<0.01$, relative fold changes of miRNA levels in BEL-7402/5-FU cells relative to BEL-7402 cells $(n=3)$.

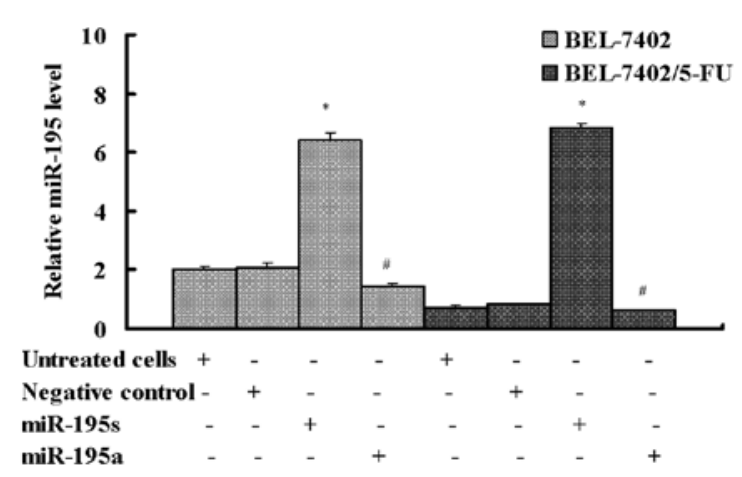

Figure 2. Transfection of different miR-195 vectors altering the expression of miR-195. BEL-7402 and BEL-7402/5-FU were transfected with miR-195s, miR-195a or control for $48 \mathrm{~h}$, and RNA were isolated and analyzed by realtime PCR. ${ }^{*} \mathrm{P}<0.05$ and ${ }^{\#} \mathrm{P}<0.05$ compared to other groups $(\mathrm{n}=3)$.

USA. Data were expressed as mean \pm SD and analyzed by one-way analysis of variance (ANOVA) and least significant difference (LSD) test. Statistical significance is displayed as ${ }^{*} \mathrm{P}<0.05$.

\section{Results}

BEL-7402/5-FU cells display altered expression of miRNAs from BEL-7402. To identify miRNA expression in BEL-7402 and BEL-7402/5-FU cells, we performed miRNAs expression profiling using MiRCURY LNA Arrays. As shown in Table I, hsa-miR-195 was down-regulated in BEL-7402/5-FU cells as compared to BEL-7402 cells. Real-time PCR confirmed the down-regulation of miRNA-195 in (Fig. 1).

MiR-195 sensitizes BEL-7402/5-FU cells to 5-FU. We determined whether miR-195 regulates apoptosis in HCC-derived cell lines. Sense and anti-sense miR-195 sequences were inserted into a miRNA vector, generating pcM-195s and pcM-195a that expressing mature and anti-sense sequences of miR-195, respectively. A vector that expresses a hairpin shRNA with limited homology to any known sequences of human genome was used as a negative control. As expected. miR-195s dramatically increased miR-195 expression in both 
Table I. Data of the microarray between BEL-7402 and BEL7402/5-FU tumor cells.

A, Up-regulated miRs

\begin{tabular}{lcc}
\hline MiR name & Fold change & P-value \\
\hline hsa-miR-192 & 2.4632 & 0.0797 \\
hsa-miR-194 & 2.0494 & 0.1094 \\
B, Down-regulated miRs & & \\
\hline
\end{tabular}

\begin{tabular}{|c|c|c|}
\hline MiR name & Fold change & P-value \\
\hline hsa-miR-195 & 0.0818 & 0.0292 \\
\hline hsa-miR-199a-5p & 0.0669 & 0.0186 \\
\hline hsa-miR-18a & 0.4218 & 0.0299 \\
\hline hsa-miR-127-3p & 0.0841 & 0.0067 \\
\hline hsa-miR-122 & 0.2007 & 0.0070 \\
\hline hsa-miR-486-3p & 0.2929 & 0.0032 \\
\hline hsa-miR-371-5p & 0.3115 & 0.0056 \\
\hline hsa-miR-20b* & 0.3224 & 0.0047 \\
\hline hsa-miR-32* & 0.4390 & 0.0068 \\
\hline hsa-miR-429 & 0.0397 & 0.0007 \\
\hline hsa-miR-335 & 0.1180 & 0.0012 \\
\hline hsa-miR-518c* & 0.1183 & 0.0024 \\
\hline hsa-miR-32 & 0.1561 & 0.0054 \\
\hline hsa-miR-374b & 0.2841 & 0.0033 \\
\hline hsa-miR-361-3p & 0.0841 & 0.0006 \\
\hline hsa-miR-98 & 0.1114 & 0.0021 \\
\hline hsa-miR-31 & 0.2779 & 0.0044 \\
\hline hsa-miR-151-5p & 0.2789 & 0.0052 \\
\hline hsa-miR-10a* & 0.0015 & 0.00002 \\
\hline hsa-miR-378 & 0.0693 & 0.0009 \\
\hline hsa-miR-130b & 0.0711 & 0.0007 \\
\hline hsa-miR-503 & 0.1175 & 0.0011 \\
\hline hsa-miR-30e & 0.4438 & 0.0078 \\
\hline hsa-miR-96 & 0.4622 & 0.0067 \\
\hline hsa-miR-7 & 0.4652 & 0.0071 \\
\hline hsa-miR-801 & 0.4676 & 0.0058 \\
\hline hsa-miR-10a & 0.0007 & 0.00001 \\
\hline hsa-miR-500 & 0.0481 & 0.0005 \\
\hline hsa-miR-590-5p & 0.0778 & 0.0009 \\
\hline hsa-miR-491-5p & 0.3687 & 0.0026 \\
\hline hsa-miR-301a & 0.0558 & 0.0002 \\
\hline hsa-miR-99b* & 0.0895 & 0.0006 \\
\hline hsa-miR-146-5p & 0.3380 & 0.0019 \\
\hline hsa-miR-519d & 0.3617 & 0.0027 \\
\hline hsa-miR-18b & 0.4339 & 0.0079 \\
\hline hsa-miR-148b & 0.0592 & 0.0004 \\
\hline hsa-miR-18a* & 0.8180 & 0.0089 \\
\hline hsa-miR-340 & 0.1920 & 0.0017 \\
\hline hsa-miR-584 & 0.4592 & 0.0028 \\
\hline hsa-miR-17* & 0.2485 & 0.0098 \\
\hline
\end{tabular}

Table I. Continued.

B, Down-regulated miRs

\begin{tabular}{lcc}
\hline MiR name & Fold change & P-value \\
\hline hsa-miR-210 & 0.1327 & 0.0077 \\
hsa-miR-492 & 0.1811 & 0.0013 \\
hsa-miR-193a-3p & 0.2543 & 0.0041 \\
hsa-miR-422a_MM2 & 0.1369 & 0.0016
\end{tabular}

Down-regulated and up-regulated miRNAs with fold changes and p-values in BEL-7402/5-FU relative to BEL-7402 cells. Out of 536 detected miRNA, 46 miRNAs were differentially expressed between BEL-7402 and BEL-7402/5-FU cells. Among these miRNA, 2 were up-regulated and 44 down-regulated. Of note, miR-195 was the one of expressed miRNA in BEL-7402/5-FU compared to BEL-7402 cell line.

BEL-7402 and BEL-7402/5-FU cells, and miR-195a repressed miR-195 in BEL-7402 (Fig. 2).

MTT and flow cytometry were performed to determine metabolic activity and apoptosis rate, respectively. MiR-195s transfection reduced metabolic activity and increased apoptosis rate of BEL-7402 and BEL-7402/5-FU cells induced by 5 -FU. The transfection of miR-195a had no significant effect on the cell lines (Fig. 3). These results suggest miR-195 improves drug sensitivity of 5-FU on BEL-7402 and BEL-7402/5-FU cells.

BEL-7402/5-FU cells express different protein level of Bcl-w, $B c l-2, B c l-X L$, and Bax from BEL-7402. The development of drug resistance in various cancer cells has been linked to a reduced susceptibility to drug-induced apoptosis. This has been attributed in some part to the overexpression of anti-apoptotic proteins, such as Bcl-2 and Bcl-XL (18). Therefore, we sought to investigate whether the resistance of BEL-7402/5-FU cells to $5-\mathrm{FU}$ is a consequence of overexpression of anti-apoptotic members of the Bcl-2 family. We performed Western blot analysis to examine the expression of Bcl-w, Bcl-2 and Bcl-XL in BEL-7402 and BEL-7402/5-FU cells. BEL-7402/5-FU cells had a higher expression of Bcl-w, Bcl-2 and Bcl-XL than the BEL-7402 cells. We also found that the BEL-7402/5-FU cells had a lower expression of Bax (a pro-apoptotic member of the Bcl-2 family) as compared to BEL-7402 cells (Fig. 4). Previous studies have shown that the pro-apoptotic members of the Bcl-2 family mediate cytochrome c release and cell apoptosis. These observations imply that decreased miR-195 levels might be involved in the regulation of Bcl-w, Bcl-2, Bcl-XL and Bax expression. Thus, we hypothesized that the removal of miRNA-195 inhibition on anti-apoptotic gene expression would facilitate the development of drug resistance in BEL-7402/5-FU.

MiR-195 decreases Bcl-w, Bcl-2, Bcl-XL expression and increases Bax expression. Next, we determined whether miR-195 is involved in regulating the expression of Bcl-w, Bcl-2, Bcl-XL and Bax, and the sensitivity to 5-FU. We transfected 

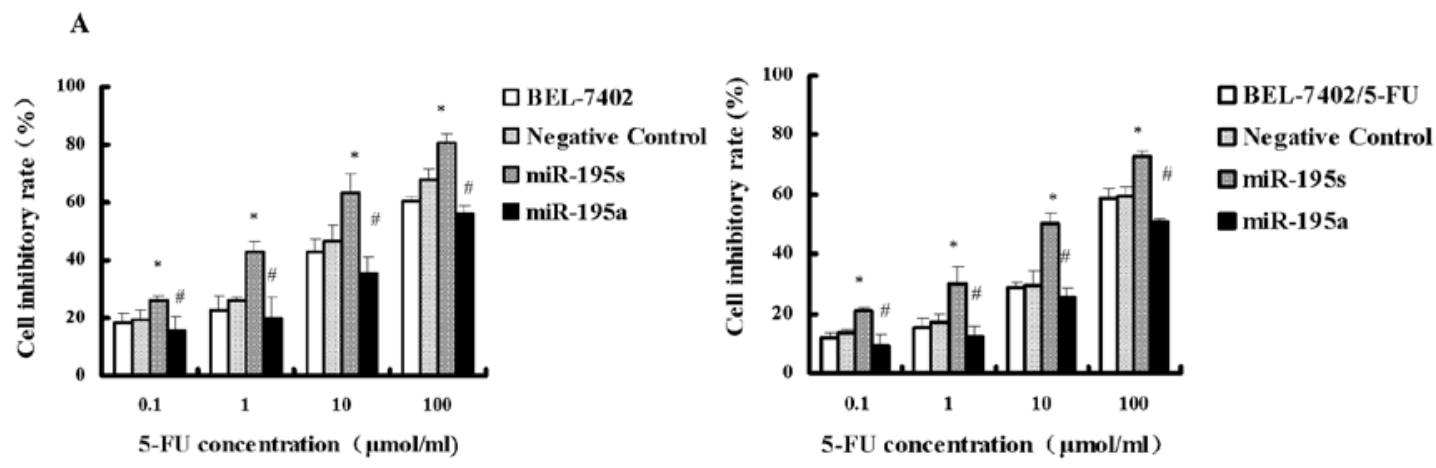

B
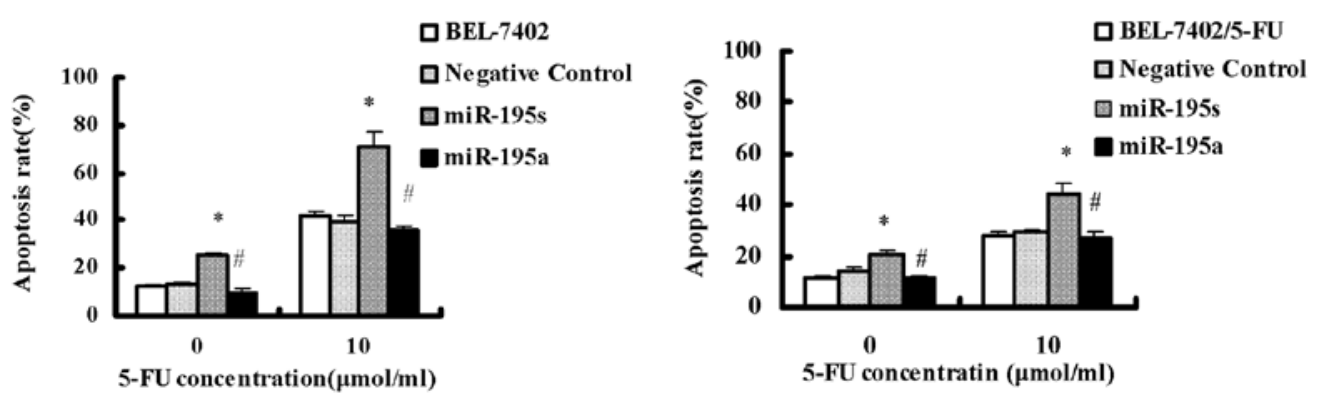

Figure 3. miR-195 increases the sensitivity of 5-FU on BEL-7402 and BEL-7402/5-FU cells. (A) Stable transfected BEL-7402 and BEL-7402/5-FU cells with miR-195s or miR-195a, negative control or non-treatment were seeded on 96-well plates, respectively. Next day, cells were exposed to different concentration of 5-FU for $24 \mathrm{~h}$. Cells were harvested and the percentage of cell inhibition was determined by MTT assays. (B) BEL-7402 and BEL-7402/5-FU cells were transfected with miR-195s, miR-195a, negative control, or non-treatment, and $24 \mathrm{~h}$ later cells were treated with $10 \mu \mathrm{mol} / \mathrm{ml}$ of 5 -FU for $48 \mathrm{~h}$. Cell apoptosis rates were evaluated by flow cytometry, and the percentage of apoptotic cells was calculated. ${ }^{*} \mathrm{P}<0.05$ and ${ }^{\#} \mathrm{P}<0.05$, compared to other groups ( $\mathrm{n}=3$ ).
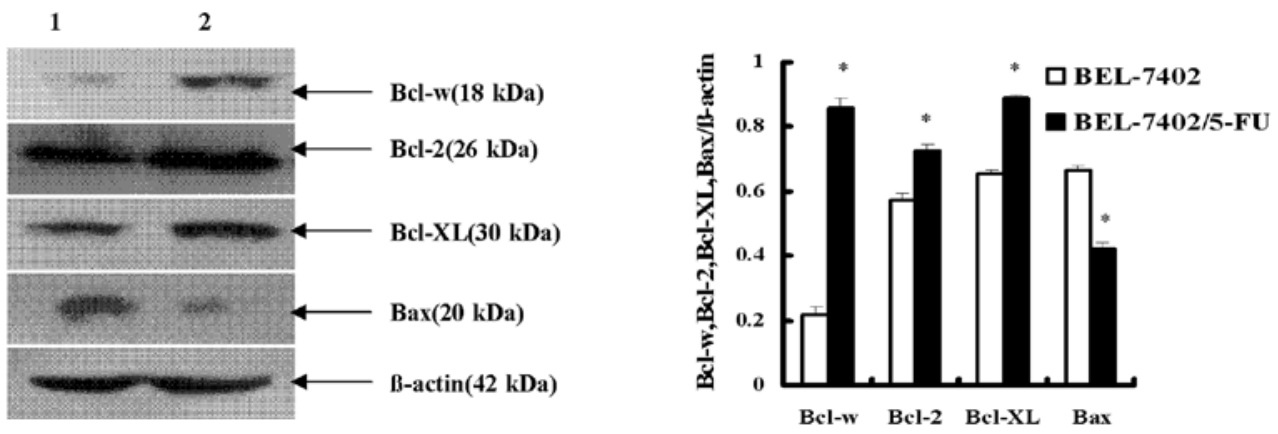

Figure 4. (A) Expression difference of Bcl-w, Bcl-2, Bcl-XL and Bax in BEL-7402 and BEL-7402/5-FU cells. Western blot analysis was performed to detect protein expression difference from two cells, relative protein level was normalized to actin. ${ }^{*} \mathrm{P}<0.05$, BEL-7402/5-FU cells compared to BEL-7402 cells ( $\mathrm{n}=3$ ).

BEL-7402 and BEL-7402/5-FU cells with either miR-195s, miR-195a or negative plasmid. The miR-195s significantly decreased Bcl-w, Bcl-2 and Bcl-XL mRNA. However, the Bax mRNA level was significantly elevated in both cell lines. As expected, transfection of miR-195a increased the expression of Bcl-w, Bcl-2 and Bcl-XL mRNA in BEL-7402 cells (Fig. 5A and $\mathrm{B})$.

Western blots were performed to determine protein levels. $\mathrm{Bcl}-\mathrm{w}, \mathrm{Bcl}-2$ and $\mathrm{Bcl}-\mathrm{XL}$ protein levels were repressed in miR195s transfected BEL-7402 and BEL-7402/5-FU cells, whereas Bax protein levels were increased in both cell lines. In addition, miR-195a increased protein expression of Bcl-w, Bcl-2 and Bcl-XL in both cell lines (Fig. 5C and D). These results suggest that miR-195 down-regulates anti-apoptotic Bcl-2 family members and up-regulates Bax genes in BEL-7402 and BEL-7402/5-FU cells.

MiR-195 acts directly on the Bcl-w 3'-UTR. In order to identify putative miR-195 targets that may contribute to tumor genesis, an in silico strategy was applied. By querying PicTar (16) and TargetScan (17), Bcl-w was identified as a putative miR-195 target gene by both programs. The prediction results and score are listed in Fig. 6A and B; as a validated miR-195 target, CCNG1 is shown as a reference. To validate the observation from Pictar and TargetScan querying, a 750-bp fragment of the 3'-UTR of Bcl-w containing the putative miR-195 binding site was cloned into the psiCHECK-2 reporter vector. As shown in Fig. 6C, the miR-195 expression vector significantly repressed the expression of reporter 
A
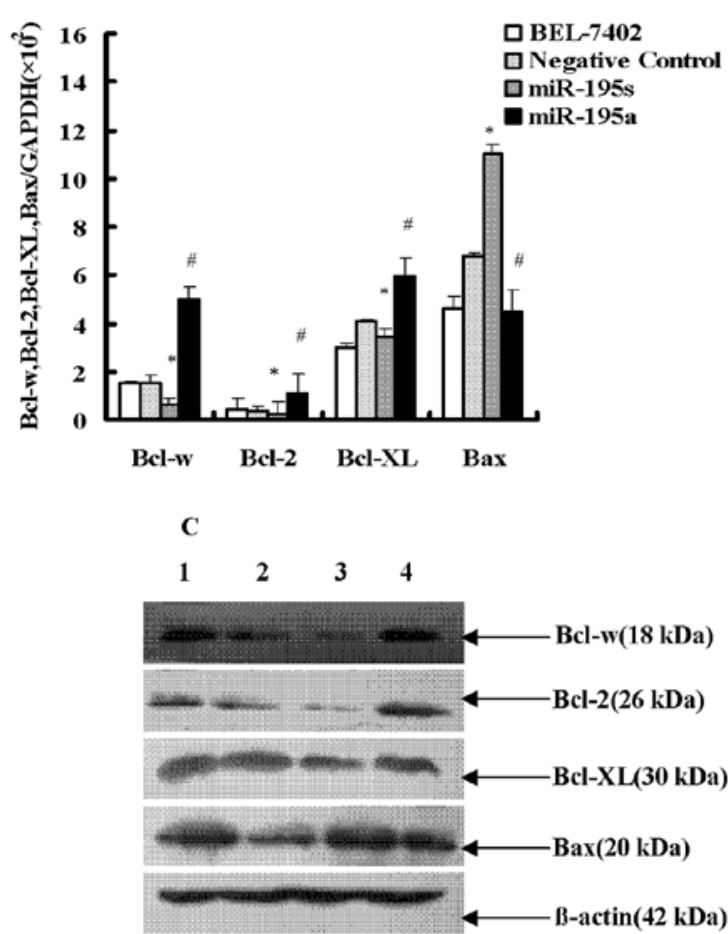

D

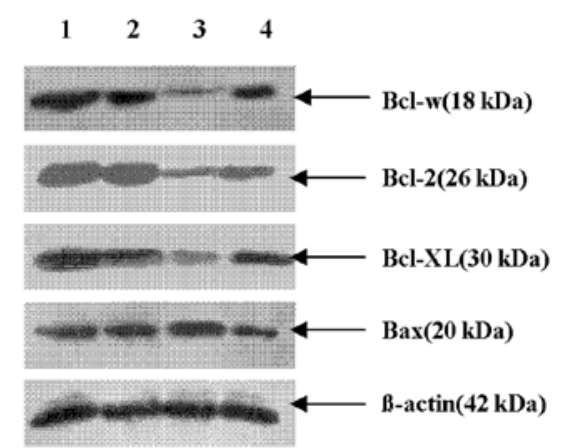

B
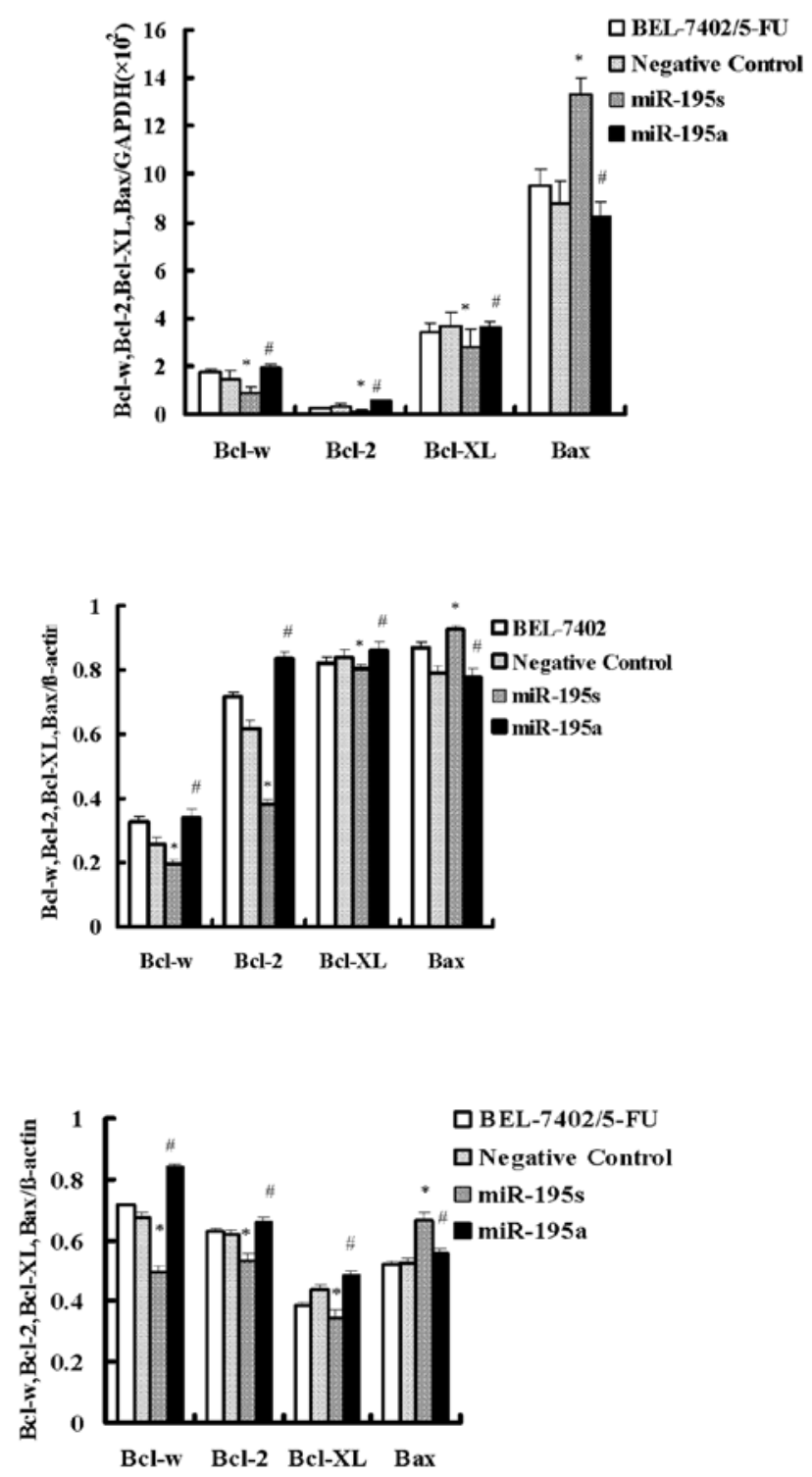

Figure 5. miR-195 regulates the expression Bcl-2 family members and Bax genes. BEL-7402 and BEL-7402/5-FU were transfected with miR-195s, miR-195a, negative control or non-treatment. (A) RNA were isolated and real-time PCR were performed to detect relative mRNA level of detected Bcl-w, Bcl-2, Bcl-XL and Bax genes. (B and C) Western blot analysis was applied to determine the protein level of Bcl-w, Bcl-2, Bcl-XL and Bax genes. Relative levels of mRNA and protein were normalized GAPDH and actin, respectively. ${ }^{*} \mathrm{P}<0.05$ and ${ }^{\#} \mathrm{P}<0.05$, compared to other groups $(\mathrm{n}=3)$.

construct, and anti-sense miR-195 increased the expression of the reporter construct in both BEL-7402 and BEL-7402/5-FU cells. These results demonstrate that miR-195 could directly inhibit Bcl-w expression at post-transcriptional level through its 3'-UTR.

\section{Discussion}

Research effort has been intensely focused on studying the role of altered miRNA expression in human malignancies. miRNA expression signatures seem to hold great promise in tumor characterization and could be potential diagnostic and prognostic markers for cancer diagnosis and treatment (19). In addition, approaches interfering with miRNA function are considered in cancer research (20). It is known that certain microRNAs impart drug resistance (21) or sensitivity (22) to cancer cells. However, drug resistance, an obstacle to curative treatment of solid tumors, occurs frequently via suppression of apoptosis, a process controlled by pro- and anti-apoptotic members of the Bcl-2 protein family.

Members of the Bcl-2 family proteins can be divided into two subfamilies; one is the anti-apoptotic proteins such as Bcl-2 and Bcl-XL, and the other is the pro-apoptotic proteins such as Bax, Bad and Bid (23). Among the Bcl-2 protein family members, overexpression of $\mathrm{Bcl}-2$ prevent chemotherapeutic agent-induced apoptosis associated with altered mitochondria membrane (24).

The balance between Bcl-2 family members defines whether a cell will live or die. As the ratio between each repressors and death promoters in the Bcl-2 family will determine the sensitivity of cells to apoptotic stimuli, the findings suggest that the changed expression patterns of Bcl-2 
A

Position 777.783 of BCL2L2 3' UTR $\quad 5^{\prime}$... UGUGCAUUAUGCACUUGCUGCUG... |l| $|1||| \mid$

hsa-miR-195

3' CGgUUAUAAaGaCACGacGaU

B

HsBcl-w:5'-GCTGCACTTTCCAAGGTGCTAAGATTGCTGCTCTCCA-3' PtBcl-w:5'-GCTGCACTTTCCAAGGTGCTAAGATTGCTGCTCTCCA-3' MmBcl-w:5'-GCTGCACTTTCCAAGGTGCTAAGATTGCTGCTCTCCA-3' RnBcl-w:5'-GCTGCACTTTCCAAGGTGCTAAGATTGCTGCTCTCCA-3' CfBcl-w: 5'-GCT GCACTTTCCAAGGTGCTAAGATTGCTGCTCTCCA-3'

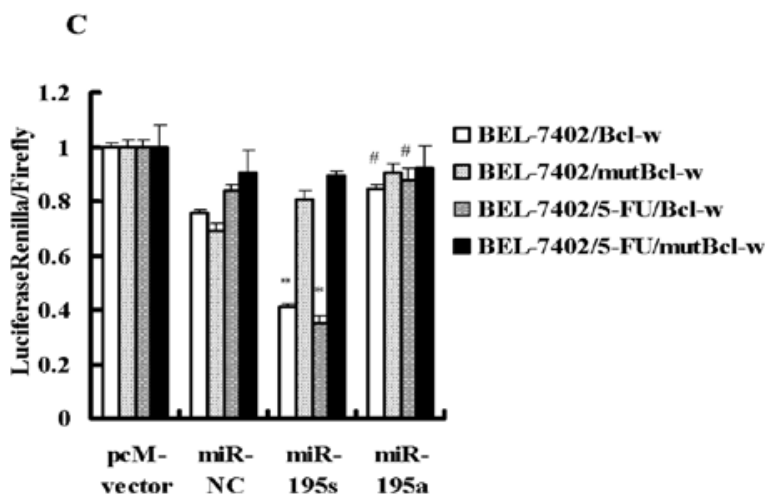

Figure 6. Effect of the putative miR-195 binding site derived from the Bcl-w 3'-UTR on luciferase expression. (A) Putative binding sites of miR-195 in the Bcl-w 3'-UTR regions are determined by TargetScan and Pictar. (B) Bcl-w 3'-UTR sequences that contain the putative miR-195 targeting site are highly conserved in human, chimpanzee (Ensembl Transcript), mouse, rat, dog. (C) Dual luciferase assay was performed in BEL-7402 and BEL-7402/5-FU cells transfected with luciferase construct alone, cotransfected with miR-195s, miR-195a or negative control. Firefly luciferase construct containing mutant (mutpsi-Bcl-w) target site of the Bcl-w 3'-UTR was generated and transfected as indicated. Firefly luciferase activity was normalized to Renilla luciferase activity for each sample $(\mathrm{n}=3)$. ${ }^{*} \mathrm{P}<0.05$ and ${ }^{~} \mathrm{P}<0.05$, compared to BEL-7402/ Bcl-w or BEL-7402/5-FU/Bcl-w.

family proteins in liver cancer cells may be involved in the resistance (25).

Several miRNAs have been reported to be involved in controlling apoptosis and cancer formation $(8,26)$, and the validated target genes of miR-195, which is down-regulated in HCC, are CCND1,CDK6, E2F3 (10). Here, miR-195 is suggested to function as a tumor suppressor in CRC development, which is consistent with its roles in hepatocellular carcinoma and adrenocortical carcinoma (27). However, in chronic lymphocytic leukemia and breast cancer, miR-195 expression is reported to be elevated in these malignancies (28-30). Hence, deregulation of miR-195 may be different in different types of cancer, and the roles of miR-195 in carcinogenesis and progression can not be simply concluded as a tumor suppressor or oncogene. In this study, we showed that miR-195 was frequently down-regulated in HCC cell lines. Ectopic expression of miR-195 suppressed HCC and colorectal carcinoma cells to form colonies in vitro and to develop tumors in vivo (reference). The underlying mechanism that is responsible for the decreased expression of miR-195 in $\mathrm{HCC}$ is still unknown. Here, we reported that miR-195 represses Bcl-w expression by directly targeting the 3'-UTR region of Bcl-w mRNA. MiR-195 was shown to inhibit Bcl-w at the post-transcriptional level in HCC-derived BEL-7402 and BEL-7402/5-FU cell lines.

We observed the effect of miR-195 on cellular sensitivity to anti-cancer drugs. 5-fluorouracil (5-FU) was used to treat advanced primary hepatocellular carcinoma in clinic, but drug resistance is usually problematic. In this study, BEL-7402/5-FU cells showed a high expression of Bcl-w, Bcl-2 and Bcl-XL and a lower expression of Bax than in BEL-7402 cells. Transfecting miR-195 vector into BEL-7402/5-FU cells resulted in the down-regulation of Bcl-w, Bcl-2 and Bcl-XL. MiR-195 transfected cells have a higher rate of 5-FU induced cell death than in normal, negative vector and miR-195 inhibitor transfected cells. It could be hypothesized that miR-195 might inhibit cell proliferation mainly through suppressing the expression Bcl-w, Bcl-2 and Bcl-XL.

In summary, our results strongly suggest that miR-195 might sensitize cell to 5-FU-induced apoptosis by suppressing the expression of Bcl-w via a direct binding of miR-195 to the 3'UTR of Bcl-w mRNA. The elevated miR-195 expression shows promise as a new strategy for the treatment of hepatocellular carcinoma.

\section{Acknowledgements}

This study was funded by the National Natural Sciences Foundation of China (no. 30900625), the Youth Foundation of Education Department of Hunan Province, China (no. 08A059) and supported by the construct program of the key discipline in Hunan province.

\section{References}

1. Seeff LB and Hoofnagle JH: Epidemiology of hepatocellular carcinoma in areas of low hepatitis B and hepatitis C endemicity. Oncogene 25: 3771-3777, 2006.

2. Di Bisceglie AM: Issues in screening and surveillance for hepatocellular carcinoma. Gastroenterology 127 (5 Suppl 1): S104-S107, 2004.

3. Adams JM and Cory S: The Bcl-2 protein family: arbiters of cell survival. Science 281: 1322-1326, 1998.

4. Takehara T, Liu X, Fujimoto J, Friedman SL and Takahashi H: Expression and role of Bcl-xL in human hepatocellular carcinomas. Hepatology 34: 55-61, 2001.

5. Thorgeirsson SS, Lee JS and Grisham JW: Functional genomics of hepatocellular carcinoma. Hepatology 43 (2 Suppl 1): S145-S150, 2006.

6. Fabregat I, Roncero C and Fernandez M: Survival and apoptosis: a dysregulated balance in liver cancer. Liver Int 27: 155-162, 2007.

7. Lee RC and Ambros V: An extensive class of small RNAs in Caenorhabditis elegans. Science 294: 862-864, 2001

8. Skaftnesmo KO, Prestegarden L, Micklem DR and Lorens JB: MicroRNAs in tumorigenesis. Curr Pharm Biotechnol 8: 320-325, 2007.

9. Hobert O: Gene regulation by transcription factors and microRNAs. Science 319: 1785-1786, 2008.

10. $\mathrm{Xu} \mathrm{T}, \mathrm{Zhu} \mathrm{Y}, \mathrm{Xiong} \mathrm{Y}, \mathrm{Ge} \mathrm{YY}$, Yun JP and Zhuang SM: MicroRNA-195 suppresses tumorigenicity and regulates G1/S transition of human hepatocellular carcinoma cells. Hepatology 50: 113-121, 2009.

11. Liu L, Chen L, Xu Y, Li R and Du X: microRNA-195 promotes apoptosis and suppresses tumorigenicity of human colorectal cancer cells. Biochem Biophys Res Commun 400: 236-240, 2010. 
12. Gibson L, Holmgreen SP, Huang DC, Bernard O, Copeland NG, Jenkins NA, Sutherland GR, Baker E, Adams JM and Cory S: bcl-w, a novel member of the bcl-2 family, promotes cell survival. Oncogene 13: 665-675, 1996.

13. Kitamura S, Kondo S, Shinomura Y, Kanayama S, Miyazaki Y, Kiyohara T, Hiraoka S and Matsuzawa Y: Met/HGF receptor modulates bcl-w expression and inhibits apoptosis in human colorectal cancers. Br J Cancer 83: 668-673, 2000.

14. Shackel NA, McGuinness PH, Abbott CA, Gorrell MD and McCaughan GW: Insights into the pathobiology of hepatitis C virus-associated cirrhosis: analysis of intrahepatic differential gene expression. Am J Pathol 160: 641-654, 2002.

15. Lu J, Getz G, Miska EA, Alvarez-Saavedra E, Lamb J, Peck D, Sweet-Cordero A, Ebert BL, Mak RH, Ferrando AA, Downing JR, Jacks T, Horvitz HR and Golub TR: MicroRNA expression profiles classify human cancers. Nature 435: 834-838, 2005.

16. Krek A, Grun D, Poy MN, Wolf R, Rosenberg L, Epstein EJ, MacMenamin P, da Piedade I, Gunsalus KC, Stoffel M and Rajewsky N: Combinatorial microRNA target predictions. Nat Genet 37: 495-500, 2005.

17. Grimson A, Farh KK, Johnston WK, Garrett-Engele P, Lim LP and Bartel DP: MicroRNA targeting specificity in mammals: determinants beyond seed pairing. Mol Cell 27: 91-105, 2007

18. Reed JC: Regulation of apoptosis by bcl-2 family proteins and its role in cancer and chemoresistance. Curr Opin Oncol 7: 541-546, 1995.

19. Xia L, Zhang D, Du R, Pan Y, Zhao L, Sun S, Hong L, Liu J and Fan D: miR-15b and miR-16 modulate multidrug resistance by targeting BCL2 in human gastric cancer cells. Int J Cancer 123 372-379, 2008.

20. Wu W, Sun M, Zou GM and Chen J: MicroRNA and cancer: Current status and prospective. Int J Cancer 120: 953-960, 2007.

21. Miller TE, Ghoshal K, Ramaswamy B, Roy S, Datta J, Shapiro CL, Jacob S and Majumder S: MicroRNA-221/222 confers tamoxifen resistance in breast cancer by targeting p27Kip1. J Biol Chem 283: 29897-29903, 2008.
22. Nasser MW, Datta J, Nuovo G, Kutay H, Motiwala T, Majumder S, Wang B, Suster S, Jacob ST and Ghoshal K: Down-regulation of micro-RNA-1 (miR-1) in lung cancer. Suppression of tumorigenic property of lung cancer cells and their sensitization to doxorubicin-induced apoptosis by miR-1. J Biol Chem 283: 33394-33405, 2008.

23. Decaudin D, Geley S, Hirsch T, Castedo M, Marchetti P, Macho A, Kofler R and Kroemer G: Bcl-2 and Bcl-XL antagonize the mitochondrial dysfunction preceding nuclear apoptosis induced by chemotherapeutic agents. Cancer Res 57: 62-67, 1997.

24. Tong X, Lin S, Fujii M and Hou DX: Molecular mechanisms of echinocystic acid-induced apoptosis in HepG2 cells. Biochem Biophys Res Commun 321: 539-546, 2004.

25. Luo D, Cheng SC and Xie Y: Expression of Bcl-2 family proteins during chemotherapeutic agents-induced apoptosis in the hepatoblastoma HepG2 cell line. Br J Biomed Sci 56: 114-122, 1999

26. Jovanovic $M$ and Hengartner MO: miRNAs and apoptosis: RNAs to die for. Oncogene 25: 6176-6187, 2006.

27. Soon PS, Tacon LJ, Gill AJ, Bambach CP, Sywak MS, Campbell PR, Yeh MW, Wong SG, Clifton-Bligh RJ, Robinson BG and Sidhu SB: miR-195 and miR-483-5p identified as predictors of poor prognosis in adrenocortical cancer. Clin Cancer Res 15: 7684-7692, 2009.

28. Heneghan HM, Miller N, Lowery AJ, Sweeney KJ, Newell J and Kerin MJ: Circulating microRNAs as novel minimally invasive biomarkers for breast cancer. Ann Surg 251: 499-505, 2010.

29. Zhang H, Su SB, Zhou QM and Lu YY: Differential expression profiles of microRNAs between breast cancer cells and mammary epithelial cells. Ai Zheng 28: 493-499, 2009.

30. Zanette DL, Rivadavia F, Molfetta GA, Barbuzano FG, ProtoSiqueira R, Silva-Jr WA, Falcao RP and Zago MA: miRNA expression profiles in chronic lymphocytic and acute lymphocytic leukemia. Braz J Med Biol Res 40: 1435-1440, 2007. 